\title{
Employment Interventions in Health Settings: A Systematic Review and Synthesis
}

\author{
Andrew D. Pinto, MD, CCFP, \\ FRCPC, MSc ${ }^{1,2,3,4}$ \\ Nadba Hassen, MPH ${ }^{1}$ \\ Amy Craig-Neil, MSc ${ }^{1}$ \\ 'The Upstream Lab, Centre for Urban \\ Health Solutions, Li Ka Shing Knowledge \\ Institute, St Michael's Hospital, Toronto, \\ Ontario, Canada \\ ${ }^{2}$ Department of Family and Community \\ Medicine, St Michael's Hospital, Toronto, \\ Ontario, Canada \\ ${ }^{3}$ Department of Family and Community \\ Medicine, Faculty of Medicine, University \\ of Toronto, Toronto, Ontario, Canada \\ ${ }^{4}$ Dalla Lana School of Public Health, \\ University of Toronto, Toronto, Ontario, \\ Canada
}

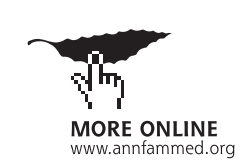

Conflicts of interest: authors report none.

\section{CORRESPONDING AUTHOR}

Andrew D. Pinto, MD, CCFP, FRCPC, MSc St Michael's Hospital 410 Sherbourne St, 4th Fl

Toronto, Ontario, Canada M4X 1K2 andrew.pinto@utoronto.ca

\begin{abstract}
PURPOSE Employment is a key social determinant of health. People who are unemployed typically have worse health than those employed. Illness and disability can result in unemployment and be a barrier to regaining employment. We combined a systematic review and knowledge synthesis to identify both studies of employment interventions in health care settings and common characteristics of successful interventions.
\end{abstract}

METHODS We searched the peer-reviewed literature (1995-2017), and titles and abstracts were screened for inclusion and exclusion criteria by 2 independent reviewers. We extracted data on the study setting, participants, intervention, methods, and findings. We also conducted a narrative synthesis and iteratively developed a conceptual model to inform future primary care interventions.

RESULTS Of 6,729 unique citations, 88 articles met our criteria. Most articles (89\%) focused on people with mental illness. The majority of articles (74\%) tested interventions that succeeded in helping participants gain employment. We identified 5 key features of successful interventions: (1) a multidisciplinary team that communicates regularly and collaborates, (2) a comprehensive package of services, (3) one-on-one and tailored components, (4) a holistic view of health and social needs, and (5) prospective engagement with employers.

CONCLUSIONS Our findings can inform new interventions that focus on employment as a social determinant of health. Although hiring a dedicated employment specialist may not be feasible for most primary care organizations, pathways using existing resources with links to external agencies can be created. As precarious work becomes more common, helping patients engage in safe and productive employment could improve health, access to health care, and well-being.

Ann Fam Med 2018;16:447-460. https://doi.org/10.1370/afm.2286.

\section{INTRODUCTION}

$\mathrm{E}$ mployment status is a key social determinant of health. ${ }^{1,2}$ Being employed influences our financial security, sense of self, social connections, and social status. Unemployment is associated with worse physical and mental health at the individual level, and is correlated with poorer health at the community level ${ }^{3-6}$ and higher mortality rates. ${ }^{7.8}$ Employment status plays an important mediating role in the strong relationship between income and health. ${ }^{7}$ Beyond income, a number of individual and contextual factors influence the relationship of employment with health, including gender identity, race and ethnicity, immigration status, and social class..$^{910}$ The relationship between employment and health is bidirectional. Those with chronic health issues are less likely to enter and remain in the workforce, and are more likely to require assistance with attaining employment. ${ }^{11-14}$

Helping people gain employment is often the role of charitable organizations, government agencies, and in some cases, the private sector; however, the health sector may also have a role. ${ }^{15,16} \mathrm{~A}$ number of studies have evaluated employment interventions embedded in health settings, including Vocational Rehabilitation, Supported Employment, and Indi- 
vidual Placement and Support (Table 1). ${ }^{12,17-26}$ These models emerged in the 1970s from community-based mental health care. ${ }^{27,28}$

More recently, primary care organizations have invested in upstream interventions to address the social determinants of health, ${ }^{29-34}$ including addressing unemployment. For example, interventions based on the Health Leads model use volunteers to connect patients with community resources, including employment. ${ }^{35}$ Medical-legal partnerships may assist patients who have been denied wages or fired ${ }^{36}$ although they do not typically focus on assisting them in gaining employment. ${ }^{37}$ No previous review has thoroughly examined employment interventions in health settings or identified successful components of interventions that move patients from unemployment to employment. Our objective was to identify interventions implemented within health care settings that assisted patients with gaining employment, and to ascertain common characteristics of successful interventions, in order to inform new ways to address employment as a social determinant of health.

\section{METHODS}

We carried out a systematic review to identify all relevant studies of interventions within health settings that sought to help unemployed patients gain employment, to identify which interventions were successful and to estimate the efficacy of different interventions. We blended this method with a knowledge synthesis to build a conceptual model of how these interventions work, to inform future interventions.

We followed the Preferred Reporting Items for Systematic Reviews and Meta-Analyses (PRISMA) guidelines for systematic reviews. ${ }^{38}$ Our protocol was registered with the International Prospective Register of Systematic Reviews (PROSPERO, registration: CRD42016049518). We developed a search strategy in consultation with an information specialist. To identify
Table 1. Types of Employment Interventions Within Health Care Settings

Individual Placement and A Supported Employment approach developed by Becker and Drake in $1994 .^{18,19}$

Key principles include (1) approach focuses on competitive employment (ie, positions available to those without severe mental illness), (2) any individual who wishes to work in a competitive job is eligible, (3) a rapid job search approach is used so that individuals can start working as quickly as possible, (4) employment specialists or team is closely integrated with the mental health team, (5) individual preferences are respected and considered, and (6) ongoing and individualized support is provided as long as necessary. ${ }^{12}$

A program that reportedly integrates vocational programs with medical services; however, it does not follow a specific program such as Individual Placement and Support.

Clubhouses use work-ordered days, which involves participation in activities to develop participants' motivation to get involved in transitional employment. ${ }^{19,20} \mathrm{~A}$ primary component of the clubhouse model is transitional employment, which consists of the following ${ }^{19(p 42)}$ :

- Realistic job experience (entry-level employment)

- A staff worker first performs tasks with new placements

- Part-time employment (15 to 20 hours/week)

- Temporary (6 to 9 months)

- Staff members guarantee a replacement if participant is absent

- Tolerates job failures

- Job coaching at work site

- Employees encouraged to work at clubhouse when not at work

In a number of studies, the intervention could not be classified as any of the interventions above. This group was heterogeneous. For example, one article considered having only an employment specialist to be an intervention. ${ }^{20}$

studies that would be most relevant to current employment conditions ${ }^{4,39}$ we limited our search of the peerreviewed literature to articles published since 1995. We searched the following databases: Ovid MEDLINE, PubMed, Embase, EBM Reviews (Cochrane Database of Systematic Reviews, Database of Abstracts of Reviews of Effects, Cochrane Central Register of Controlled Trials, Cochrane Methodology Register, Health Technology Assessment, NHS Economic Evaluation Database), Scopus, CINAHL, Theses Canada Portal, and ProQuest Dissertations and Theses Global (Supplemental Appendix 1, available at http://www. annfammed.org/content/16/5/447/supp1/DC1/).

Titles and abstracts were screened by 2 independent reviewers. Exclusion criteria are shown in Figure 1. Health care settings were defined as locations where the main purpose was to deliver health services, including primary care centers, hospitals, emergency departments, community health centers, health centers in prisons, and walk-in clinics. We excluded studies that combined data from both health care and non-health care settings and state Vocational Rehabilitation agen- 
cies. An individual was considered to be employed if they had paid work, and unemployed if they did not have paid work, were not on a leave of absence from work, or had no job to return to. We did not exclude articles on the basis of patient characteristics (such as age, sex, or diagnosis). We focused on studies conducted in high-income countries (as defined by the World Bank) because low- and middle-income countries are considerably different contexts in terms of health care settings, economic conditions, and social supports. We did not limit our search by any specific language. The full texts agreed on by both reviewers were screened to determine whether they met inclusion criteria. If there was a disagreement about whether an article should be included, the study team and principal investigator met to jointly make a final decision.

We developed a standardized, pilot-tested data extraction form and used it to extract data from included articles (Supplemental Appendix 2, available at http://www.annfammed.org/content/16/5/447/suppl/ DC1/). The quality of individual studies was assessed using standardized tools. Randomized controlled trials were assessed using the Cochrane Collaboration Risk of Bias Tool. ${ }^{40}$ Observational studies were assessed using a 9-point rigor scale developed by the World Health Organization and Johns Hopkins. ${ }^{41}$

We anticipated that the studies identified would be heterogeneous with respect to design, employment outcomes, and follow-up time points, which would preclude a meta-analysis on a single end point. We conducted a narrative synthesis, however, to bring together the key components of successful interventions, and defined a positive employment outcome as an individual gaining paid work. Two authors (N.H., A.CN.) independently read all full-text articles included, inductively developed themes from the studies, and iteratively developed the final categories. A conceptual model was developed and iteratively refined by the entire study team as the reviewers' understanding of interventions and their components evolved.

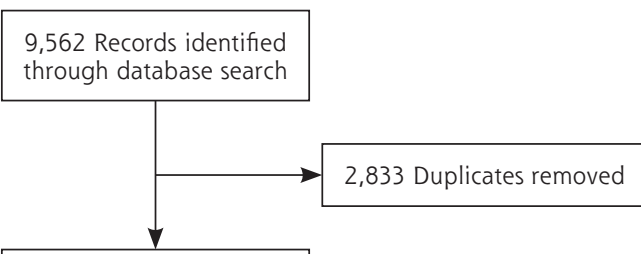

6,729 Titles and abstracts screened by 2 independent reviewers

6,272 Records excluded

457 Full-text articles assessed for eligibility

369 Full-text articles excluded, with following reasons:

19 Study had no employment intervention

87 Not all study participants unemployed at baseline

80 Study had no quantified employment outcome
88 Articles included in review and synthesis
57 Not in a health care setting

30 Had focus outside area of interest (intermediate outcomes, job retention, predictors of employment)

50 Conference abstracts, editorials, or case studies of individuals

19 Literature reviews

4 Not in a high-income country

4 No full-text article available

19 Other
PRISMA = Preferred Reporting Items for Systematic Reviews and Meta-Analyses.

\section{RESULTS}

\section{Article Characteristics}

A total of 88 articles ultimately met our criteria and were included (Figure 1, Supplemental Appendix 2). Forty-eight articles (54\%) reported on studies conducted in the United States. Of the total, 48 (54\%) described randomized controlled trials, 31 (35\%) prospective cohort studies, and $9(10 \%)$ retrospective cohort studies. Across all study types, 58 (66\%) had a control or comparison group.

The quality of the 48 randomized controlled trials was moderate, with a low risk of bias with respect to randomization method (34 trials), allocation concealment (32 trials), blinding of outcome assessors (36 trials), incomplete outcome data (37 trials), and selective outcome reporting (27 trials) (Table 2). ${ }^{20,24-26,42-85}$

Of the 40 observational studies, the majority included preintervention and postintervention data (28 studies) and followed a cohort (39 studies), but fewer than one-half of the studies included control or comparison groups (13 studies) or controlled for potential confounders (15 studies) (Table 3). ${ }^{11,23,86-123}$ In general, randomization was not applicable. The follow-up rate was reported or applicable in only 19 studies and was at least $80 \%$ in just 
Table 2. Assessment of the Risk of Bias in Randomized Controlled Trials $(n=48)$

Authors, Year

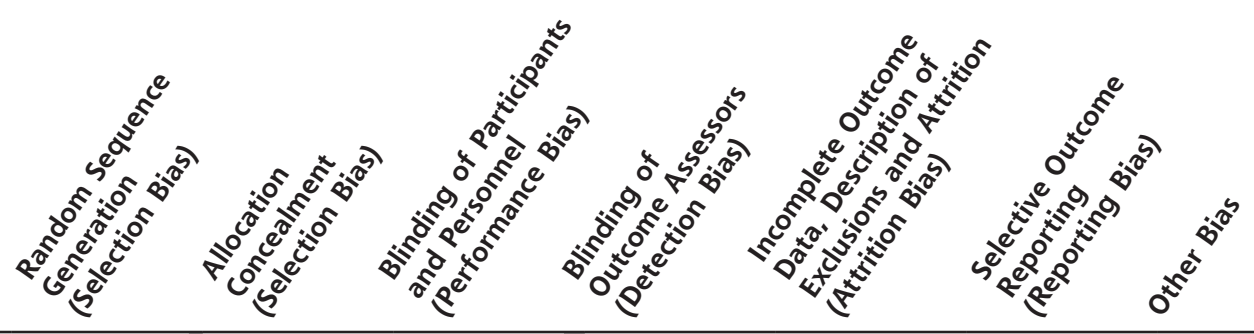

Au et $\mathrm{al}_{1}{ }^{42} 2015$

Becker et al, ${ }^{43} 1996$

Bejerholm et al, ${ }^{44} 2017$

Bejerholm et al, ${ }^{45} 2015$

Bell et $\mathrm{al}_{,}{ }^{46} 2014$

Bell et al ${ }_{1}^{47} 2008$

Blankertz and Robin-

son, ${ }^{20} 1996$

$+\quad ?$

Bond et al, ${ }^{48} 2015$

Bond et al, ${ }^{49} 2013$

Bond et al, ${ }^{50} 2016$

Bond et al, ${ }^{51} 2007$

Bond et al, ${ }^{52} 1995$

Burns et al, ${ }^{53} 2015$

Burns et al, ${ }^{54} 2007$

Burns and Catty, ${ }^{24} 2008$

$?$

$-$

$-$

$+$

$+\quad+$

Cook et al, ${ }^{55} 2008$

Cook et al, ${ }^{25} 2005$

Cook et al, ${ }^{56} 2005$

Craig et al, ${ }^{57} 2014$

Fraser et al, ${ }^{58} 2008$

Gold et al, ${ }^{26} 2006$

Heslin et al, ${ }^{59} 2011$

Hoffmann et al, ${ }^{60} 2012$

Hoffmann et al, ${ }^{61} 2014$

Howard et al, ${ }^{62} 2010$

Lehman et al,,$^{63} 2002$

LePage et al, ${ }^{64} 2016$

Macias et al,, 52006

McGurk et al, ${ }^{66} 2016$

McGurk et al, ${ }^{67} 2015$

McGurk et al, ${ }^{68} 2009$

McGurk et al, ${ }^{69} 2005$

Michon et $\mathrm{al}_{1}{ }^{70} 2014$

Mueser et al, ${ }^{71} 2011$

Mueser et al, ${ }^{72}$ 2004a

Mueser et al, ${ }^{73} 2004 b$

Oshima et al, ${ }^{74} 2014$

$\begin{array}{ll}+ & + \\ + & +\end{array}$

-
-
-
-
-

+
+
+
+
+
+
+

+
+
-

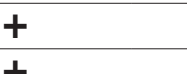

$?+$

$+$

$+$

? ?

$+$

$\begin{array}{lll}- & -\end{array}$

$\begin{array}{ll}+ & + \\ ? & ?\end{array}$

$-$

$-$

?

? ?

$+\quad+$

? $\quad-$

$\begin{array}{lll}2 & +\end{array}$

$\begin{array}{llll}? & ? & - \\ + & ? & - & +\end{array}$

$\begin{array}{ll}+ & + \\ + & +\end{array}$

$+\quad+$

$+\quad-$

$+\quad-$

$+$

$+$


Table 2. Assessment of the Risk of Bias in Randomized Controlled Trials $(n=48)$ (continued)

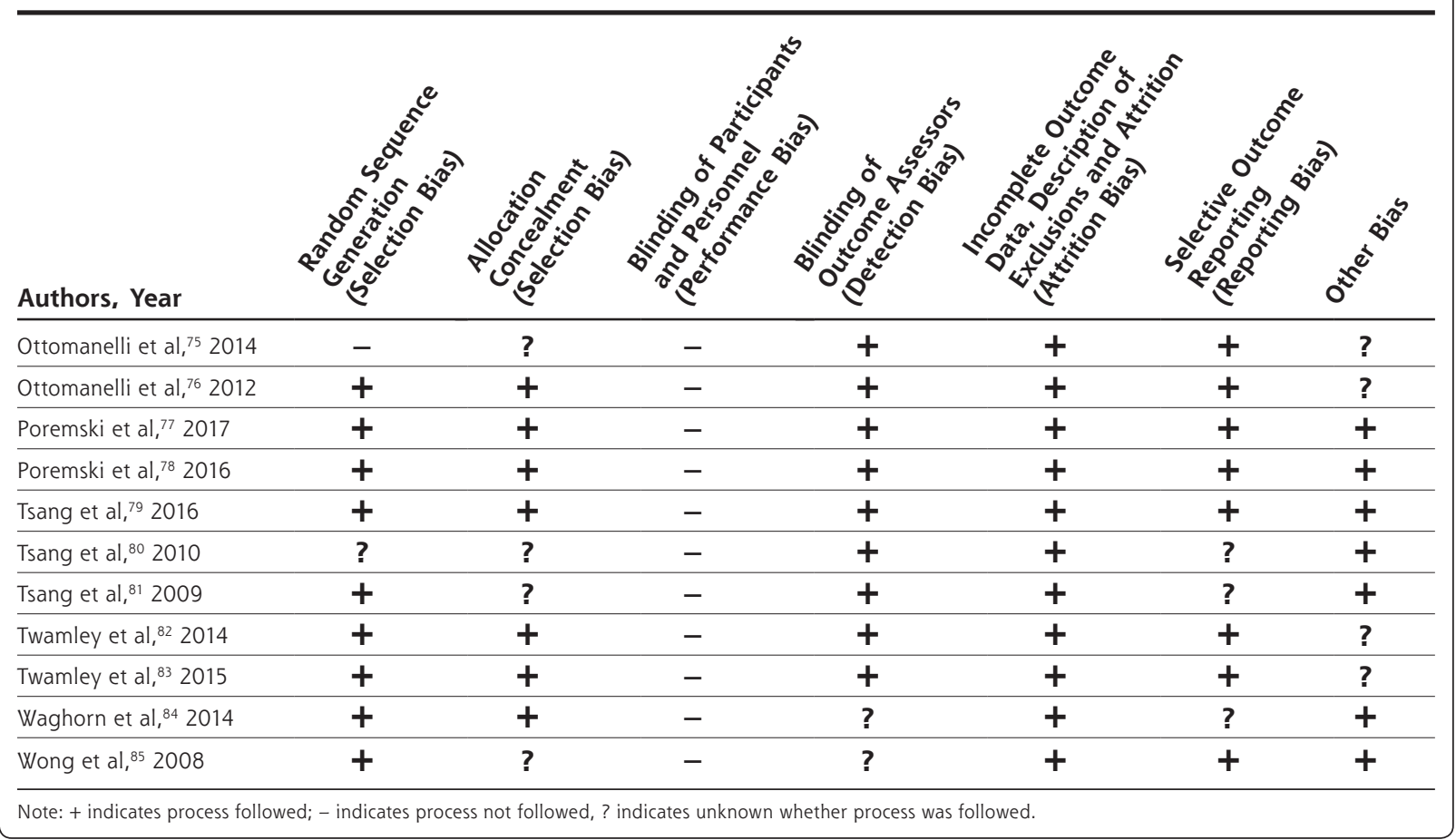

10 of them. The average rigor score was 3 out of 9, suggesting the quality of the observational studies was low.

Most of the 88 articles (89\%) focused on patients with mental illness. The type of health setting was known for 81 (92\%), with the majority situated in community mental health centers or their equivalent. Only 3 were located in settings that also provided primary care. Two of these studies were carried out in Sweden, one involving mobile teams that integrated primary care and mental health services for people with severe mental illness ${ }^{48}$ and the other engaging a similar population through outpatient clinics. ${ }^{49}$ One study took place within a US community health center with a focus on people living with HIV/AIDS. ${ }^{96}$ All 3 were positive studies, with significantly improved employment outcomes in the intervention groups.

\section{Interventions and Outcomes}

Although the 88 articles reported on a variety of interventions, the majority (73\%) focused on Supported Employment interventions. Intervention groups ranged in size from 13 to 1,340 participants, with 1 article reporting on 27,408 participants from 17 sites. ${ }^{115}$ When multiple articles referred to the same study, we counted these participants only once. In total, our review reports on 42,428 individuals who received an employment intervention.

Of the 48 randomized controlled trials, 37 (77\%) achieved significantly higher employment outcomes in the intervention group compared with the traditional vocational services or control group. Similarly, 28 (70\%) of the 40 observational studies demonstrated positive employment outcomes for study participants. Two employment interventions in the United Kingdom were unsuccessful (ie, did not have significantly increased rates of employment among the study population), and the authors found that the context of the United Kingdom compared with that of the United States contributed to this difference. ${ }^{62,102}$ Because Individual Placement and Support is not integrated into the mental health system in the United Kingdom, as is typical in the United States, the employment service is often provided by an external agency. ${ }^{62}$ The United Kingdom also had a lack of incentives for employers to hire employees with mental illnesses, and there were differences in government support.

We examined the success rate at 1 year, or the time point closest to 1 year, excluding a single study that did not report on the success of the intervention. ${ }^{106}$ Across successful studies, the average increase in any type of employment was $51 \%$ (range $=11 \%$ to $100 \%$ ). If we consider only the studies that had comparison groups or controls, the average increase in employment was $28 \%$ (range $=11 \%$ to $79 \%$ ).

\section{Key Features of Successful Interventions}

Our synthesis brought together the 5 key features common in successful interventions, with a focus on 
Table 3. Assessment of the Rigor of Observational Studies $(n=40)$

\begin{tabular}{|c|c|c|c|c|c|}
\hline Author(s), Year & Study Design & $\begin{array}{c}\text { Study Design } \\
\text { Includes Pre- and } \\
\text { Post-Intervention } \\
\text { Data }\end{array}$ & $\begin{array}{l}\text { Study Design } \\
\text { Includes Control } \\
\text { or Comparison } \\
\text { Group }\end{array}$ & $\begin{array}{l}\text { Study Design } \\
\text { Includes } \\
\text { Cohort }\end{array}$ & $\begin{array}{l}\text { Comparison } \\
\text { Groups Equivalent } \\
\text { at Baseline on } \\
\text { Sociodemographics }\end{array}$ \\
\hline Alverson et al, ${ }^{86} 1995$ & Prospective cohort & Yes & No & Yes & $\mathrm{n} / \mathrm{a}$ \\
\hline Becker et al, ${ }^{87} 2007$ & Retrospective cohort & Yes & No & Yes & $\mathrm{n} / \mathrm{a}$ \\
\hline Becker et al, ${ }^{88} 2001$ & Prospective cohort & No & Yes & No & Not reported \\
\hline Becker et al, ${ }^{11} 1999$ & $\begin{array}{l}\text { Retrospective cohort } \\
\text { (secondary analysis) }\end{array}$ & No & No & Yes & $\mathrm{n} / \mathrm{a}$ \\
\hline Bowie et al, ${ }^{89} 2017$ & Prospective cohort & Yes & Yes & Yes & Yes \\
\hline Burt, ${ }^{23} 2012$ & Prospective cohort & Yes & Yes & Yes & Yes \\
\hline Chang et al, ${ }^{90} 2016$ & Prospective cohort & Yes & No & Yes & $\mathrm{n} / \mathrm{a}$ \\
\hline Chiu and Wong, ${ }^{91} 2001$ & Retrospective cohort & Yes & No & Yes & $\mathrm{n} / \mathrm{a}$ \\
\hline Chuang et al, ${ }^{92} 2015$ & Retrospective cohort & No & No & Yes & $\mathrm{n} / \mathrm{a}$ \\
\hline Dresser et al, ${ }^{93} 2015$ & Prospective cohort & Yes & No & Yes & $\mathrm{n} / \mathrm{a}$ \\
\hline Ellison et al, ${ }^{94} 2015$ & Prospective cohort & Yes & No & Yes & Not reported \\
\hline Fuller et al, ${ }^{95} 2000$ & Retrospective cohort & Yes & No & Yes & $\mathrm{n} / \mathrm{a}$ \\
\hline Kielhofner et al, ${ }^{96} 2004$ & Prospective cohort & Yes & No & Yes & $\mathrm{n} / \mathrm{a}$ \\
\hline Landolt et al, ${ }^{97} 2016$ & Prospective cohort & Yes & No & Yes & $\mathrm{n} / \mathrm{a}$ \\
\hline Leff et al, ${ }^{98} 2005$ & Prospective cohort & Yes & No & Yes & $\mathrm{n} / \mathrm{a}$ \\
\hline LePage et al, ${ }^{99} 2011$ & Prospective cohort & Not reported & Yes & Yes & Not reported \\
\hline LePage et al, ${ }^{100} 2013$ & Prospective cohort & Not reported & Yes & Yes & Yes \\
\hline Lucca et al, ${ }^{101} 2004$ & Retrospective cohort & Not reported & No & Yes & Not reported \\
\hline Marwaha et al, ${ }^{102} 2014$ & Prospective cohort & Yes & Yes & Yes & No \\
\hline McCarthy et al, ${ }_{1}^{103} 1998$ & Prospective cohort & No & No & Yes & $\mathrm{n} / \mathrm{a}$ \\
\hline Morris et al, ${ }^{104} 2014$ & Prospective cohort & Yes & No & Yes & $\mathrm{n} / \mathrm{a}$ \\
\hline Ottomanelli et al, ${ }^{105} 2017$ & Prospective cohort & Yes & No & Yes & $\mathrm{n} / \mathrm{a}$ \\
\hline Ottomanelli et al, 1062015 & Prospective cohort & Yes & No & Yes & $\mathrm{n} / \mathrm{a}$ \\
\hline Pandiani et al, $^{107} 2004$ & $\begin{array}{l}\text { Retrospective cohort } \\
\text { (secondary analysis) }\end{array}$ & Not reported & Yes & Yes & Yes \\
\hline $\begin{array}{l}\text { Porteous and Wag- } \\
\text { horn, }{ }^{108} 2007 \\
\end{array}$ & Prospective cohort & No & No & Yes & $\mathrm{n} / \mathrm{a}$ \\
\hline Puig et al, ${ }^{109} 2016$ & Prospective cohort & Yes & No & Yes & $\mathrm{n} / \mathrm{a}$ \\
\hline Reddy et al $_{t}^{110} 2016$ & Prospective cohort & No & No & Yes & $\mathrm{n} / \mathrm{a}$ \\
\hline Roush, ${ }^{111} 2009$ & $\begin{array}{l}\text { Retrospective cohort } \\
\text { (secondary analysis) }\end{array}$ & Yes & No & Yes & $\mathrm{n} / \mathrm{a}$ \\
\hline Rüsch et al, ${ }^{112} 2014$ & Retrospective cohort & No & No & Yes & $\mathrm{n} / \mathrm{a}$ \\
\hline Sato et al, ${ }^{113} 2014$ & Prospective controlled & Yes & Yes & Yes & Yes \\
\hline Tan et al, ${ }^{114} 2016$ & Prospective cohort & Yes & No & Yes & $\mathrm{n} / \mathrm{a}$ \\
\hline Van Veggel et al, ${ }^{115} 2015$ & $\begin{array}{l}\text { Prospective cohort/ } \\
\text { parallel design }\end{array}$ & Yes & Yes & Yes & Yes \\
\hline Waghorn et al, ${ }^{116} 2015$ & $\begin{array}{l}\text { Prospective cohort/ } \\
\text { parallel design }\end{array}$ & Yes & No & Yes & No \\
\hline Watzke et al, ${ }^{117} 2009$ & Prospective cohort & Yes & Yes & Yes & Yes \\
\hline Waynor and Gill,, 2015 & Prospective cohort & Yes & $\mathrm{n} / \mathrm{a}$ & Yes & $\mathrm{n} / \mathrm{a}$ \\
\hline Williams et al, ${ }^{119} 2015$ & Prospective cohort & No & Yes & Yes & Yes \\
\hline Wittich et al, ${ }^{120} 2013$ & Prospective cohort & Yes & No & Yes & $\mathrm{n} / \mathrm{a}$ \\
\hline Wong et al, ${ }^{121} 2000$ & Prospective cohort & Yes & Yes & Yes & No \\
\hline Wong et al, 1222001 & Prospective cohort & Yes & Yes & Yes & Yes \\
\hline $\begin{array}{l}\text { Zanis and Coviello, }{ }^{123} \\
2001\end{array}$ & Prospective cohort & Yes & No & Yes & $\mathrm{n} / \mathrm{a}$ \\
\hline
\end{tabular}




\section{Comparison \\ Groups Equivalent \\ at Baseline on \\ Outcome Measures}

Random Assignment

(Group or Individual) to the Intervention

$$
\text { n/a }
$$

Not reported

n/a

n/a

$\mathrm{n} / \mathrm{a}$

Not reported

n/a

No

No

$\mathrm{n} / \mathrm{a}$

$\mathrm{n} / \mathrm{a}$

$\mathrm{n} / \mathrm{a}$

$\mathrm{n} / \mathrm{a}$

$\mathrm{n} / \mathrm{a}$

Not reported

No n/a

$n / a \quad n / a$

n/a n/a

n/a n/a

Yes Yes

Yes Yes

No No

No No

n/a n/a

$\mathrm{n} / \mathrm{a} \quad \mathrm{n} / \mathrm{a}$

$n / a \quad n / a$

$\mathrm{n} / \mathrm{a}$

$\mathrm{n} / \mathrm{a}$

$\mathrm{n} / \mathrm{a} \quad \mathrm{n} / \mathrm{a}$

$\begin{array}{ll}n / a & n / a \\ n / a & n / a \\ n / a & n / a\end{array}$

n/a No

Yes No

n/a n/a

Yes No

No No

$\begin{array}{ll}\text { Yes } & \text { No } \\ \text { n/a } & \text { n/a } \\ \text { Yes } & \text { n/a } \\ \text { n/a } & \text { n/a } \\ \text { Yes } & \text { n/a } \\ \text { Yes } & \text { n/a } \\ \text { n/a } & \text { n/a }\end{array}$

Participants

Randomly Selected for Assessment

No

Not reported

n/a

No

No

$\mathrm{n} / \mathrm{a}$

No

$\mathrm{n} / \mathrm{a}$

$\mathrm{n} / \mathrm{a}$

No

n/a

No

n/a

$\mathrm{n} / \mathrm{a}$

No

No

No

No

No

$\mathrm{n} / \mathrm{a}$

no

$\mathrm{n} / \mathrm{a}$

No

Not reported

No

No

No

No

No

n/a

No

No

Not reported

n/a

n/a

$\mathrm{n} / \mathrm{a}$

$\mathrm{n} / \mathrm{a}$

Not reported

No

Control for

Potential Confounders

Not reported

Not reported

Not reported

No

Yes

Yes

Not reported

Not reported

No

Not reported

No

No

Yes

Not reported

Yes

Yes

Yes

No

Yes

No

No

No

n/a

Not reported

Yes

Not reported

Not reported

Yes
Yes
Yes

$\begin{array}{ll}\text { n/a } & 3 \\ \text { No } & 2 \\ \text { n/a } & 3\end{array}$

Yes

Yes

n/a

No

Yes

$\begin{array}{ll}\text { Yes } & 3 \\ \text { No } & 6\end{array}$

$\begin{array}{ll}\text { No } & 2 \\ \text { No } & 5\end{array}$

No

Yes

No

$\mathrm{n} / \mathrm{a}$

No

Yes

Not reported

Not reported

Not

\begin{tabular}{cl} 
No & 3 \\
Yes & 7 \\
\hline No & 2 \\
No & 4 \\
Yes & 3 \\
\hline Not reported & 5 \\
Not reported & 5 \\
Yes & 3
\end{tabular}


those that were supported by findings from multiple studies that were rigorous (Supplemental Appendix 3, available at http://www.annfammed.org/ content/16/5/447/suppl/DC1/). Although each feature is presented separately, there are certainly areas of overlap and intersection (Figure 2). All of these features were present in the studies of interventions that were delivered in settings that also provided primary care. ${ }^{48-50}$

\section{A Multidisciplinary}

Intervention Team With Open Communication to Address Patient Needs

Successful interventions were patient centered and engaged a multidisciplinary team, composed of health care workers and employment specialists, who communicated consistently. ${ }^{20,65,76}$ The majority of articles (61 of 88), including high-quality randomized controlled trials, described how integrated, multidisciplinary, coordinated services were important characteristics of the intervention. Integrating clinical and employment services achieved significantly higher competitive employment rates compared with the control. ${ }^{63}$ Having the entire team in the same space allowed for better understanding of each other's roles, responsibilities, and skills across disciplines, which better enabled the patient's needs to be met. ${ }^{120}$

Eleven studies described ongoing communication across the multidisciplinary team as a key component of the intervention.* Ongoing communication between health and employment specialists ensured that the patient's health needs and strengths were considered when looking for potential work and that any challenges were addressed once they secured employment. ${ }^{69}$

Successful intervention teams were patient centered, focused on helping patients meet their goals and take control of the process. Trust between the employment specialist and the patient helped participants

*References 20,61,67,69,84,85,90,94,105,114,116 discuss challenges. ${ }^{124}$ Five successful studies $77,78,86,116,118$ cited the importance of the patient's relationship with the physician, while an unsuccessful Individual Placement and Support intervention ${ }^{62}$ found that mental health professionals did not expect patients to work and had low general expectations of them.

Patients Receive a Package of Services Including Expert Advice, a Job Search, Feedback, Networking, Education and Training, and Peer Mentorship Successful interventions provided patients with access to advice from an expert (eg, a case manager), a rapid and competitive job search, ongoing feedback and support, networking to employers, education and training, and peer mentor support. Sixty-six studies described having dedicated full-time employment specialists or case managers as a critical component of employment interventions. Job coaches were experienced in the rehabilitation of people with mental illness and 
had maximum caseloads of 12 participants to ensure that support was provided to each. ${ }^{60}$ Forty-six studies described how several successful interventions provided rapid competitive job searches and matching. For people with severe mental health illnesses, acquiring employment early or within the first months of an intervention can be important because motivation and confidence may decline later on. ${ }^{75}$

Fifty-four studies described the importance of ongoing feedback and support in their employment interventions. More specifically, 9 studies found that using positive reinforcement and encouragement, and providing hope to patients was important in successful employment interventions. Positive reinforcement could be provided through certificates, awards, and public recognition..$^{20}$ Five studies found that networking and providing individuals with access to job contacts were useful. ${ }^{25,88,95,115,120}$ Forty-seven studies described how education, training on topics such as interview skills, and developing social skills or on-site job training was important and associated with better employment outcomes. Thirteen studies used peer mentors to provide support to individuals through initiatives such as monthly peer support groups to assist with vocational development. ${ }^{114}$

\section{Services Are One on One and Tailored}

Successful interventions provided one-on-one services to individuals that were tailored to their job preferences, skills, education, and previous work experience. Forty studies described how such services enhanced the intervention. A one-to-one interaction allowed for a strong relationship between the employment specialist and each client. ${ }^{51}$ Fifty studies described how interventions were tailored and individualized to participants. Employment specialists worked with each individual to ensure that they based their search for competitive employment on that individual's educational background, previous experiences, and preference for a work area. ${ }^{60}$

\section{Services Are Holistic and Take a Comprehensive View of Social Needs}

Successful interventions provided a holistic model of care and addressed social determinants of health aside from employment. Eight studies acknowledged the importance of addressing these other determinants, such as housing and having appropriate clothes to wear to work. ${ }^{23}$ Integration of the employment specialist into the health care team brought the social determinants of health to the forefront of primary care. ${ }^{23,76,90,102}$ Having an employment service champion promoted organizational buy-in. ${ }^{102}$ At health care centers where Supported Employment interventions were provided, the clinical staff were more likely to ask their patients about employment status. ${ }^{76}$ Employment interventions have been noted to positively influence clinician attitudes, helping them to see the importance of supporting employment outcomes. ${ }^{125}$

\section{Intervention Team Works With and Engages Employers} In successful interventions, employers were able to receive support, education, and incentives, and in some cases provided accommodation for disabilities. Eight studies described how employers received support from the intervention team. In an intervention for people living with AIDS, staff worked to ensure that the employer was supported in responding to challenges. ${ }^{96}$ Interventions included providing employers with education from health care professionals, answering questions, and pointing out benefits of hiring those with mental illness, as well as employer training workshops to destigmatize mental illness. ${ }^{95,114}$ Six studies, including a number of observational studies that were highly rigorous, reported the advantages of employer buy-in and incentives to take on individuals with health concerns as a means of reducing barriers to entering the workforce. ${ }^{60-62,64,95,114}$ Five studies described how employers provided accommodation to employees, such as individualizing schedules. ${ }^{44,52,64,106,114}$

\section{DISCUSSION}

We identified 88 articles reporting studies of interventions in health settings that aimed to move patients from unemployment to employment. Key features of successful interventions were consistent across multiple studies. Such interventions typically deployed multidisciplinary teams that communicated well and placed patients - and their medical, psychological, and social needs-at the center. They provided a package of employment services and engaged employers proactively. Part of the role of the employment specialist was helping patients navigate different systems having different requirements. ${ }^{126}$ The impact on health remains unclear, as our review found modest improvements in quality of life, and no studies demonstrating that gaining employment altered functioning or mental health. ${ }^{127,128}$

Addressing unemployment is one way to tackle an underlying cause of poor health. Having an integrated team with health care workers and employment specialists can help to reduce barriers for patients entering the workforce. Individuals who work in settings that are not stigmatizing can experience improved self-esteem, satisfaction, and sense of empowerment. ${ }^{129}$ With health issues such as multiple sclerosis and traumatic brain injuries, early referral to an employment 
intervention was important in ensuring that patients gained employment. ${ }^{130}$ Our findings suggested that having employment interventions in health care settings integrates these services to best serve patients.

The findings of our study fit with those of other studies that have examined employment interventions, particularly those that focused on people living with mental illness. A previous review confirmed the importance of a tailored approach. ${ }^{131} \mathrm{~A}$ Cochrane systematic review of Supported Employment in severe mental illness found this approach was effective, although individual studies had substantial bias, and few examined the durability of the intervention. ${ }^{132}$ As we found, the overall quality of the evidence in this area, particularly for observational studies, was low. ${ }^{132-135}$ Variation in outcomes across employment interventions warrants exploration. ${ }^{136}$

Our study has limitations. Because of publication bias, negative studies may not have been published. Although we conducted a quality assessment of every study, there were instances wherein risk of bias or rigor of the study was unclear. Key features of the successful interventions were extracted, but these features may not be comprehensive. Certain interventions had multiple publications and may be overrepresented in this review. Finally, we could not conduct a meta-analysis because of the heterogeneous nature of the studies.

Our conceptual model can assist with the design and implementation of employment interventions within health care settings. Given that most studies included in this review occurred outside of primary care, further research will be required to evaluate how employment interventions can be integrated within first-contact, team-based, longitudinal care provided to diverse populations. Although hiring a dedicated employment specialist may not be feasible, certain team-based primary care organizations can develop a pathway for patients dealing with unemployment and precarious employment. This pathway could involve raising awareness of employment as a key social determinant of health across the primary care team, training internal staff (eg, social workers, community health workers, or system navigators) to provide support based on the key components we identified, and building relationships with external employment services.

This review is timely given that standard permanent full-time work has been on the decline in favor of part-time, contract, and other unregulated work that increases job insecurity. ${ }^{4}$ Precarious employment that is not stable and of acceptable quality can be detrimental to workers' health, and these workers have higher psychological morbidity compared with permanent workers. ${ }^{137-139}$ We defined a positive employment outcome as gaining employment of any form, yet the quality of employment (eg, wage rate, working conditions, exposure to hazards, psychological stress) that workers experience is important to consider. If the focus is simply on placing people in any job available, there is a high likelihood that these will be low-quality jobs with little security or few benefits. ${ }^{140}$ Future interventions should assess and report on the quality of jobs in a consistent manner.

Employment is an important social determinant of health, and integrating employment interventions into health care settings presents an innovative way to assist patients. These interventions are complex, and further research is required on screening for unemployment and precarious employment, ${ }_{1}^{141,142}$ and to evaluate the long-term impact of interventions across different health care settings and with diverse patients. The evidence from this systematic review demonstrates that there are key features of successful interventions in health care settings that are useful in informing future interventions. This work contributes to emerging theory that supports addressing the social determinant of health in clinical settings. ${ }^{32,143}$

To read or post commentaries in response to this article, see it online at http://www.AnnFamMed.org/content/16/5/447.

Key words: social determinants of health; employment; systematic review; work; health care settings; working conditions; chronic disease; vulnerable populations; primary care

Submitted November 16, 2017; submitted, revised, April 30, 2018; accepted May 10, 2018.

Funding support: This study was supported by a grant from the Atkinson Foundation Decent Work Fund. Dr Pinto receives salary support from the Department of Family and Community Medicine and the Li Ka Shing Knowledge Institute at St Michael's Hospital, Toronto. Dr Pinto is also supported by a Clinician-Scientist Award from the Department of Family and Community Medicine, Faculty of Medicine, University of Toronto.

Disclaimer: The study funder played no role in the design of the study, data collection, data analysis, interpretation of data, or the writing and editing of this article.

Previous presentation: Findings from this study were presented at the Trillium Research Day; May 31, 2017; Toronto, Ontario, Canada.

Acknowledgments: We appreciate the assistance of Arman Hamidian and Priyanka Chowdhury in reviewing citations and articles for this study. We are grateful to Carolyn Ziegler for her assistance in designing and carrying out the search of databases. Finally, we thank Anne Rucchetto for her assistance in editing this manuscript.

- Supplemental Materials: Available at http://www.AnnFamMed. org/content/16/5/447/suppl/DC1/.

\section{References}

1. World Health Organization. Commission on Social Determinants of Health. Geneva, Switzerland: World Health Organization; 2008.

2. Hammarström A, Janlert U. An agenda for unemployment research: a challenge for public health. Int J Health Serv. 2005;35(4):765-777. 
3. Wilkinson R, Marmot M, eds. Social Determinants of Health: The Solid Facts. 2nd ed. Geneva, Switzerland; World Health Organization, Regional Office for Europe; 2003.

4. Benach J, Muntaner C. Precarious employment and health: developing a research agenda. J Epidemiol Community Health. 2007; 61(4):276-277.

5. Iversen L, Andersen O, Andersen PK, Christoffersen K, Keiding N. Unemployment and mortality in Denmark, 1970-80. Br Med J (Clin Res Ed). 1987;295(6603):879-884.

6. Dorling D. Unemployment and health. BMJ. 2009;338:b829.

7. Stronks K, van de Mheen H, van den Bos J, Mackenbach JP. The interrelationship between income, health and employment status. Int J Epidemiol. 1997;26(3):592-600.

8. Kivimäki M, Vahtera J, Virtanen M, Elovainio M, Pentti J, Ferrie JE. Temporary employment and risk of overall and cause-specific mortality. Am J Epidemiol. 2003;158(7):663-668.

9. Artazcoz L, Borrell C, Cortès I, Escribà-Agüir V, Cascant L. Occupational epidemiology and work related inequalities in health: a gender perspective for two complementary approaches to work and health research. J Epidemiol Community Health. 2007;61(Suppl 2):ii39-ii45.

10. Benach J, Muntaner C, Santana V, chairs. Employment Conditions and Health Inequalities. Final Report to the WHO Commission on Social Determinants of Health (CSDH). http://www.who.int/ social_determinants/resources/articles/emconet_who_report.pdf. Published Sep 20, 2007. Accessed Aug 23, 2018.

11. Becker RE, Meisler N, Stormer G, Brondino MJ. Employment outcomes for clients with severe mental illness in a PACT model replication. Program for Assertive Community Treatment. Psychiatr Serv. 1999;50(1):104-106.

12. Bond GR. Supported employment: evidence for an evidence-based practice. Psychiatr Rehabil J. 2004;27(4):345-359.

13. Schuring M, Burdorf L, Kunst A, Mackenbach J. The effects of ill health on entering and maintaining paid employment: evidence in European countries. J Epidemiol Community Health. 2007;61(7): 597-604.

14. Pelkowski JM, Berger MC. The impact of health on employment, wages, and hours worked over the life cycle. Q Rev Econ Finance. 2004;44(1):102-121.

15. Goel R, Buchman S, Meili R, Woollard R. Social accountability at the micro level: One patient at a time. Can Fam Physician. 2016; 62(4):287-290, 299-302.

16. Schrecker T. Beyond 'run, knit and relax': can health promotion in Canada advance the social determinants of health agenda? Healthc Policy. 2013;9(Spec Issue):48-58.

17. Wehman P, Moon S. Critical values in employment programs for persons with developmental disabilities: A position paper. J Appl Rehabil Counsel. 1987;18(1):12-16.

18. Becker DR, Drake RE. Individual Placement and Support: a community mental health center approach to vocational rehabilitation. Community Ment Health J. 1994;30(2):193-206; discussion 207-212.

19. Corbiere M, Lecomte T. Vocational services offered to people with severe mental illness. J Mental Health. 2009;18(1):38-50

20. Blankertz L, Robinson S. Adding a vocational focus to mental health rehabilitation. Psychiatr Serv. 1996;47(11):1216-1222.

21. Crowther R, Marshal M, Bond GR, Huxley P. Vocational rehabilitation for people with severe mental illness. Cochrane Database Syst Rev. 2010;(2):CD003080.

22. Wehman P. Supported employment: toward equal employment opportunity for persons with severe disabilities. Ment Retard. 1988;26(6):357-361.

23. Burt MR. Impact of housing and work supports on outcomes for chronically homeless adults with mental illness: LA's HOPE. Psychiatr Serv. 2012;63(3):209-215.
24. Burns T, Catty J; EQOLISE Group. IPS in Europe: the EQOLISE trial. Psychiatr Rehabil J. 2008;31(4):313-317.

25. Cook JA, Leff HS, Blyler CR, et al. Results of a multisite randomized trial of supported employment interventions for individuals with severe mental illness. Arch Gen Psychiatry. 2005;62(5): 505-512.

26. Gold PB, Meisler N, Santos AB, Carnemolla MA, Williams $O H$, Keleher J. Randomized trial of supported employment integrated with assertive community treatment for rural adults with severe mental illness. Schizophr Bull. 2006;32(2):378-395.

27. Benach J, Vives A, Tarafa G, Delclos C, Muntaner C. What should we know about precarious employment and health in 2025? Framing the agenda for the next decade of research. Int J Epidemiol. 2016;45(1):232-238.

28. Lewchuk W, Clarke M, de Wolff A. Working without commitments: precarious employment and health. Work Employ Soc. 2008;22(3): 387-405.

29. Kiran T, Pinto AD. Swimming 'upstream' to tackle the social determinants of health. BMJ Qual Saf. 2016;25(3):138-140.

30. Jones MK, Bloch G, Pinto AD. A novel income security intervention to address poverty in a primary care setting: a retrospective chart review. BMJ Open. 2017;7(8):e014270.

31. DeVoe JE, Bazemore AW, Cottrell EK, et al. Perspectives in primary care: a conceptual framework and path for integrating social determinants of health into primary care practice. Ann Fam Med. 2016;14(2):104-108.

32. Pinto AD, Bloch G. Framework for building primary care capacity to address the social determinants of health. Can Fam Physician. 2017;63(11):e476-e482.

33. Aery A, Rucchetto A, Singer A, et al. Implementation and impact of an online tool used in primary care to improve access to financial benefits for patients: a study protocol. BMJ Open. 2017;7(10): e015947.

34. Orkin AM, Bharmal A, Cram J, Kouyoumdjian FG, Pinto AD, Upshur R. Clinical population medicine: integrating clinical medicine and population health in practice. Ann Fam Med. 2017;15(5):405-409.

35. Gottlieb LM, Hessler D, Long D, et al. Effects of social needs screening and in-person service navigation on child health: a randomized clinical trial. JAMA Pediatr. 2016;170(11):e162521.

36. Jackman M. Law as a tool for addressing social determinants of health. In: Ries NM, Bailey TM, Caulfield T, eds. Public Health Law and Policy in Canada. 2nd ed. Ontario, Canada: LexisNexis Canada; 2010:91-130.

37. Sandel M, Hansen M, Kahn R, et al. Medical-legal partnerships: transforming primary care by addressing the legal needs of vulnerable populations. Health Aff (Millwood). 2010;29(9):1697-1705.

38. Moher D, Liberati A, Tetzlaff J, Altman DG. Preferred reporting items for systematic reviews and meta-analyses: the PRISMA statement. BMJ. 2009;339(j):b2535.

39. Casale G, ed. The Employment Relationship: A Comparative Overview. Geneva, Switzerland: International Labour Organization; 2011.

40. Higgins J, Green S. Cochrane Handbook for Systematic Reviews of Interventions Version 5.1.0. London, United Kingdom; The Cochrane Collaboration: 2011.

41. World Health Organization, Johns Hopkins. 9-Point Rigour Scale. WHO-Johns Hopkins Synthesizing Intervention Effectiveness Project; 2012.

42. Au DW, Tsang HW, So WW, et al. Effects of integrated supported employment plus cognitive remediation training for people with schizophrenia and schizoaffective disorders. Schizophr Res. 2015; 166(1-3):297-303.

43. Becker DR, Drake RE, Farabaugh A, Bond GR. Job preferences of clients with severe psychiatric disorders participating in supported employment programs. Psychiatr Serv. 1996;47(11):1223-1226. 
44. Bejerholm U, Larsson ME, Johanson S. Supported employment adapted for people with affective disorders - a randomized controlled trial. J Affect Disord. 2017;207:212-220.

45. Bejerholm U, Areberg C, Hofgren C, Sandlund M, Rinaldi M. Individual placement and support in Sweden - a randomized controlled trial. Nord J Psychiatry. 2015;69(1):57-66.

46. Bell MD, Choi KH, Dyer C, Wexler BE. Benefits of cognitive remediation and supported employment for schizophrenia patients with poor community functioning. Psychiatr Serv. 2014;65(4):469-475.

47. Bell MD, Zito W, Greig T, Wexler BE. Neurocognitive enhancement therapy with vocational services: work outcomes at two-year follow-up. Schizophr Res. 2008;105(1-3):18-29.

48. Bond GR, Kim SJ, Becker DR, et al. A controlled trial of supported employment for people with severe mental illness and justice involvement. Psychiatr Serv. 2015;66(10):1027-1034.

49. Bond GR, Campbell K, Becker DR. A test of the occupational matching hypothesis for rehabilitation clients with severe mental illness. J Occup Rehabil. 2013;23(2):261-269.

50. Bond GR, Drake RE, Campbell K. Effectiveness of individual placement and support supported employment for young adults. Early Interv Psychiatry. 2016;10(4):300-307.

51. Bond GR, Salyers MP, Dincin J, et al. A randomized controlled trial comparing two vocational models for persons with severe mental illness. J Consult Clin Psychol. 2007;75(6):968-982.

52. Bond GR, Dietzen LL, McGrew JH, Miller LD. Accelerating entry into supported employment for persons with severe psychiatric disabilities. Rehabil Psychol. 1995;40(2):75-94.

53. Burns T, Yeeles K, Langford O, Montes MV, Burgess J, Anderson C. A randomised controlled trial of time-limited individual placement and support: IPS-LITE trial. BrJ Psychiatry. 2015;207(4):351-356.

54. Burns T, Catty J, Becker T, et al.; EQOLISE Group. The effectiveness of supported employment for people with severe mental illness: a randomised controlled trial. Lancet. 2007;370(9593):1146-1152.

55. Cook J, Blyler CR, Burke-Miller J, et al. Effectiveness of supported employment for individuals with schizophrenia: results of a multisite, randomized trial. Clin Schizophr Relat Psychoses. 2008;(April): 37-46.

56. Cook JA, Lehman AF, Drake R, et al. Integration of psychiatric and vocational services: a multisite randomized, controlled trial of supported employment. Am J Psychiatry. 2005;162(10):1948-1956.

57. Craig $T$, Shepherd G, Rinaldi M, et al. Vocational rehabilitation in early psychosis: cluster randomised trial. Br J Psychiatry. 2014; 205(2):145-150.

58. Fraser VV, Jones AM, Frounfelker R, Harding B, Hardin T, Bond GR. VR closure rates for two vocational models. Psychiatr Rehabil J. 2008;31(4):332-339.

59. Heslin $M$, Howard $L$, Leese $M$, et al. Randomized controlled trial of supported employment in England: 2 year follow-up of the Supported Work and Needs (SWAN) study. World Psychiatry. 2011; 10(2):132-137.

60. Hoffmann H, Jäckel D, Glauser S, Kupper Z. A randomised controlled trial of the efficacy of supported employment. Acta Psychiatr Scand. 2012;125(2):157-167.

61. Hoffmann H, Jäckel D, Glauser S, Mueser KT, Kupper Z. Long-term effectiveness of supported employment: 5-year follow-up of a randomized controlled trial. Am J Psychiatry. 2014;171(11):1183-1190.

62. Howard LM, Heslin M, Leese M, et al. Supported employment: randomised controlled trial. BrJ Psychiatry. 2010;196(5):404-411.

63. Lehman AF, Goldberg R, Dixon LB, et al. Improving employment outcomes for persons with severe mental illnesses. Arch Gen Psychiatry. 2002;59(2):165-172.

64. LePage JP, Lewis AA, Crawford AM, et al. Incorporating individualized placement and support principles into vocational rehabilitation for formerly incarcerated veterans. Psychiatr Serv. 2016;67(7): 735-742.
65. Macias C, Rodican CF, Hargreaves WA, Jones DR, Barreira PJ, Wang Q. Supported employment outcomes of a randomized controlled trial of ACT and clubhouse models. Psychiatr Serv. 2006; 57(10):1406-1415.

66. McGurk SR, Mueser KT, Xie H, et al. Cognitive remediation for vocational rehabilitation nonresponders. Schizophr Res. 2016;175(13):48-56.

67. McGurk SR, Mueser KT, Xie H, et al. Cognitive enhancement treatment for people with mental illness who do not respond to supported employment: a randomized controlled trial. Am J Psychiatry. 2015;172(9):852-861.

68. McGurk SR, Mueser KT, DeRosa TJ, Wolfe R. Work, recovery, and comorbidity in schizophrenia: a randomized controlled trial of cognitive remediation. Schizophr Bull. 2009;35(2):319-335.

69. McGurk SR, Mueser KT, Pascaris A. Cognitive training and supported employment for persons with severe mental illness: oneyear results from a randomized controlled trial. Schizophr Bull. 2005;31(4):898-909.

70. Michon $H$, van Busschbach JT, Stant AD, van Vugt MD, van Weeghel J, Kroon H. Effectiveness of individual placement and support for people with severe mental illness in The Netherlands: a 30-month randomized controlled trial. Psychiatr Rehabil J. 2014; 37(2):129-136.

71. Mueser KT, Campbell K, Drake RE. The effectiveness of supported employment in people with dual disorders. J Dual Diagn. 2011;7(12):90-102.

72. Mueser KT, Clark RE, Haines M, et al. The Hartford study of supported employment for persons with severe mental illness. J Consult Clin Psychol. 2004;72(3):479-490.

73. Mueser KT, Essock SM, Haines M, Wolfe R, Xie H. Posttraumatic stress disorder, supported employment, and outcomes in people with severe mental illness. CNS Spectr. 2004;9(12):913-925.

74. Oshima I, Sono T, Bond GR, Nishio M, Ito J. A randomized controlled trial of individual placement and support in Japan. Psychiatr Rehabil J. 2014;37(2):137-143.

75. Ottomanelli L, Barnett SD, Goetz LL. Effectiveness of supported employment for veterans with spinal cord injury: 2-year results. Arch Phys Med Rehabil. 2014;95(4):784-790.

76. Ottomanelli L, Goetz LL, Suris A, et al. Effectiveness of supported employment for veterans with spinal cord injuries: results from a randomized multisite study. Arch Phys Med Rehabil. 2012;93(5): 740-747.

77. Poremski D, Rabouin D, Latimer E. A randomised controlled trial of evidence based supported employment for people who have recently been homeless and have a mental illness. Adm Policy Ment Health. 2017;44(2):217-224.

78. Poremski D, Whitley R, Latimer E. Building trust with people receiving supported employment and housing first services. Psychiatr Rehabil J. 2016;39(1):20-26.

79. Tsang HW, Bell MD, Cheung V, Tam KL, Yeung WS. Integrated supported employment plus cognitive remediation training for people with schizophrenia. Hong Kong Med J. 2016;22(Suppl 2): S15-S18.

80. Tsang HW, Fung KM, Leung AY, Li SM, Cheung WM. Three year follow-up study of an integrated supported employment for individuals with severe mental illness. Aust N Z J Psychiatry. 2010;44(1): 49-58.

81. Tsang HWH, Chan A, Wong A, Liberman RP. Vocational outcomes of an integrated supported employment program for individuals with persistent and severe mental illness. J Behav Ther Exp Psychiatry. 2009;40(2):292-305.

82. Twamley EW, Jak AJ, Delis DC, Bondi MW, Lohr JB. Cognitive symptom management and rehabilitation therapy (CogSMART) for veterans with traumatic brain injury: pilot randomized controlled trial. J Rehabil Res Dev. 2014;51(1):59-70. 
83. Twamley EW, Thomas KR, Gregory AM, et al. CogSMART compensatory cognitive training for traumatic brain injury: effects over 1 year. J Head Trauma Rehabil. 2015;30(6):391-401.

84. Waghorn G, Dias S, Gladman B, Harris M, Saha S. A multi-site randomised controlled trial of evidence-based supported employment for adults with severe and persistent mental illness. Aust Occup Ther J. 2014;61(6):424-436.

85. Kin Wong K, Chiu R, Tang B, Mak D, Liu J, Chiu SN. A randomized controlled trial of a supported employment program for persons with long-term mental illness in Hong Kong. Psychiatr Serv. 2008; 59(1):84-90.

86. Alverson M, Becker DR, Drake RE. An ethnographic study of coping strategies used by people with severe mental illness participating in supported employment. Psychosocial Rehabilitation Journal. 1995;18(4):115-128.

87. Becker D, Whitley R, Bailey EL, Drake RE. Long-term employment trajectories among participants with severe mental illness in supported employment. Psychiatr Serv. 2007;58(7):922-928.

88. Becker DR, Smith J, Tanzman B, Drake RE, Tremblay T. Fidelity of supported employment programs and employment outcomes. Psychiatr Serv. 2001;52(6):834-836.

89. Bowie CR, Grossman M, Gupta M, Holshausen K, Best MW. Action-based cognitive remediation for individuals with serious mental illnesses: effects of real-world simulations and goal setting on functional and vocational outcomes. Psychiatr Rehabil J. 2017; 40(1):53-60.

90. Chang L, Douglas N, Scanlan JN, Still M. Implementation of the enhanced intersectoral links approach to support increased employment outcomes for consumers of a large metropolitan mental health service. Br J Occup Ther. 2016;79(11):643-650.

91. Chiu R, Wong K. A hospital-based supported employment service for persons with mental illness in Hong Kong. WFOT Bull. 2001; 44(Nov):5-11.

92. Chuang WF, Hwang E, Lee HL, Wu SL. An in-house prevocational training program for newly discharged psychiatric inpatients: exploring its employment outcomes and the predictive factors. Occup Ther Int. 2015;22(2):94-103.

93. Dresser K, Clark HB, Deschênes N. Implementation of a positive development, evidence-supported practice for emerging adults with serious mental health conditions: the Transition to Independence Process (tip) model. J Behav Health Serv Res. 2015;42(2): 223-237.

94. Ellison ML, Klodnick VV, Bond GR, et al. Adapting supported employment for emerging adults with serious mental health conditions. J Behav Health Serv Res. 2015;42(2):206-222.

95. Fuller TR, Oka M, Otsuka K, Yokoyama N, Liberman RP, Niwa SI. A hybrid supported employment program for persons with schizophrenia in Japan. Psychiatr Serv. 2000;51(7):864-866.

96. Kielhofner G, Braveman B, Finlayson M, Paul-Ward A, Goldbaum $\mathrm{L}$, Goldstein K. Outcomes of a vocational program for persons with AIDS. Am J Occup Ther. 2004;58(1):64-72.

97. Landolt K, Brantschen E, Nordt C, Bärtsch B, Kawohl W, Rössler W. Association of supported employment with cognitive functioning and employment outcomes. Psychiatr Serv. 2016;67(11):1257-1261.

98. Leff HS, Cook JA, Gold PB, et al. Effects of job development and job support on competitive employment of persons with severe mental illness. Psychiatr Serv. 2005;56(10):1237-1244.

99. LePage JP, Washington EL, Lewis AA, Johnson KE, Garcia-Rea EA. Effects of structured vocational services on job-search success in ex-offender veterans with mental illness: 3-month follow-up. J Rehabil Res Dev. 2011;48(3):277-286.

100. LePage JP, Lewis AA, Washington EL, Davis B, Glasgow A. Effects of structured vocational services in ex-offender veterans with mental illness: 6-month follow-up. J Rehabil Res Dev. 2013;50(2): 183-192.
101. Lucca AM, Henry AD, Banks S, Simon L, Page S. Evaluation of an Individual Placement and Support model (IPS) program. Psychiatr Rehabil J. 2004;27(3):251-257.

102. Marwaha S, Gilbert E, Flanagan S. Implementation of an employment intervention in mental health teams: a naturalistic 1-year employment outcome study in people with severe mental illness. J Ment Health. 2014;23(3):135-139.

103. McCarthy D, Thompson D, Olson S. Planning a statewide project to convert day treatment to supported employment. Psychiatr Rehabil J. 1998;22(1):30-33.

104. Morris A, Waghorn G, Robson E, Moore L, Edwards E. Implementation of evidence-based supported employment in regional Australia. Psychiatr Rehabil J. 2014;37(2):144-147.

105. Ottomanelli L, Goetz LL, Barnett SD, et al. Individual placement and support in spinal cord injury: a longitudinal observational study of employment outcomes. Arch Phys Med Rehabil. 2017; 98(8):1567-1575.e1.

106. Ottomanelli L, Barnett SD, Goetz LL, Toscano R. Vocational rehabilitation in spinal cord injury: what vocational service activities are associated with employment program outcome? Top Spinal Cord Inj Rehabil. 2015;21(1):31-39.

107. Pandiani JA, Simon MM, Tracy BJ, Banks SM. Impact of multiagency employment services on employment rates. Community Ment Health J. 2004;40(4):333-345.

108. Porteous N, Waghorn G. Implementing evidence-based employment services in New Zealand for young adults with psychosis: progress during the first five years. Br J Occup Ther. 2007;70(12): 521-526.

109. Puig O, Thomas KR, Twamley EW. Age and Improved Attention Predict Work Attainment in Combined Compensatory Cognitive Training and Supported Employment for People With Severe Mental Illness. J Nerv Ment Dis. 2016;204(11):869-872.

110. Reddy LF, Llerena K, Kern RS. Predictors of employment in schizophrenia: The importance of intrinsic and extrinsic motivation. Schizophr Res. 2016;176(2-3):462-466.

111. Roush S. The Menu Approach to supported employment for individuals with severe and persistent mental illness: Outcomes in an Oregon community based program. Work. 2009;34(1):45-51.

112. Rüsch N, Nordt C, Kawohl W, et al. Work-related discrimination and change in self-stigma among people with mental illness during supported employment. Psychiatr Serv. 2014;65(12):1496-1498.

113. Sato S, Iwata K, Furukawa SI, Matsuda Y, Hatsuse N, Ikebuchi $E$. The effects of the combination of cognitive training and supported employment on improving clinical and working outcomes for people with schizophrenia in Japan. Clin Pract Epidemiol Ment Health. 2014;10(1):18-27.

114. Tan BL, Li Z, Tan CHM. Evaluation of a national supported employment programme for people with psychiatric conditions. $\mathrm{Br}$ J Occup Ther. 2016;79(5):270-274.

115. Van Veggel R, Waghorn G, Dias S. Implementing evidence-based supported employment in Sussex for people with severe mental illness. Br J Occup Ther. 2015;78(5):286-294.

116. Waghorn G, Dias S, Gladman B, Harris M. Measuring what matters: effectiveness of implementing evidence-based supported employment for adults with severe mental illness. Int J Ther Rehabil. 2015;22(9):411-420.

117. Watzke S, Galvao A, Brieger P. Vocational rehabilitation for subjects with severe mental illnesses in Germany. A controlled study. Soc Psychiatry Psychiatr Epidemiol. 2009;44(7):523-531.

118. Waynor WR, Gill KJ. The role of hope in predicting supported employment success. J Rehabil. 2015;81(2):26-31.

119. Williams PL, Lloyd C, Waghorn G, Machingura T. Implementing evidence-based practices in supported employment on the Gold Coast for people with severe mental illness. Aust Occup Ther J. 2015;62(5):316-325. 
120. Wittich W, Watanabe DH, Scully L, Bergevin M. Development and adaptation of an employment-integration program for people who are visually impaired in Quebec, Canada. J Vis Impair Blind. 2013; 107(6):481-495.

121. Wong KK, Chiu LP, Tang SW, et al. Vocational outcomes of individuals with psychiatric disabilities participating in a supported competitive employment program. Work. 2000;14(3):247-255.

122. Wong KK, Chiu SN, Chiu LP, Tang SW. A supported competitive employment programme for individuals with chronic mental illness. Hong Kong J Psychiatry. 2001;11(2):13-18.

123. Zanis DA, Coviello D. A case study of employment case management with chronically unemployed methadone maintained clients. J Psychoactive Drugs. 2001;33(1):67-73.

124. Poremski D, Whitley R, Latimer E. Barriers to obtaining employment for people with severe mental illness experiencing homelessness. J Ment Health. 2014;23(4):181-185.

125. Chang WH, Sohn MK, Lee J, et al. Return to work after stroke: the KOSCO Study. J Rehabil Med. 2016;48(3):273-279.

126. Andersen MF, Nielsen KM, Brinkmann S. Meta-synthesis of qualitative research on return to work among employees with common mental disorder. Scand J Work Environ Health. 2012;38(2):93-104.

127. van Rijn RM, Carlier BE, Schuring M, Burdorf A. Work as treatment? The effectiveness of re-employment programmes for unemployed persons with severe mental health problems on health and quality of life: a systematic review and meta-analysis. Occup Environ Med. 2016;73(4):275-279.

128. Pinto AD, Benusic M. Workers should be able to stay home if sick. Hamilton Spectator. https://www.thespec.com/opinionstory/6180609-workers-should-be-able-to-stay-home-if-sick/. Published Dec 14, 2015. Accessed Aug 23, 2018.

129. Cook PS. Recent trends in vocational rehabilitation for people with psychiatric disability. Am Rehabil. 1997;20(4):2-12.

130. Ottomanelli L, Barnett SD, Toscano R. Individual placement and support (IPS) in physical rehabilitation and medicine: the VA spinal cord injury experience. Psychiatr Rehabil J. 2014;37(2):110-112.

131. Donker-Cools BHPM, Daams JG, Wind H, Frings-Dresen MHW. Effective return-to-work interventions after acquired brain injury: a systematic review. Brain Inj. 2016;30(2):113-131.

132. Kinoshita Y, Furukawa TA, Kinoshita K, et al. Supported employment for adults with severe mental illness. Cochrane Database Syst Rev. 2013;9(9):CD008297.

133. Trenaman LM, Miller WC, Escorpizo R; SCIRE Research Team. Interventions for improving employment outcomes among individuals with spinal cord injury: a systematic review. Spinal Cord. 2014;52(11):788-794.
134. Roels EH, Aertgeerts B, Ramaekers D, Peers K. Hospital- and community-based interventions enhancing (re)employment for people with spinal cord injury: a systematic review. Spinal Cord. 2016;54(1):2-7.

135. Carmona VR, Gómez-Benito J, Huedo-Medina TB, Rojo JE. Employment outcomes for people with schizophrenia spectrum disorder: A meta-analysis of randomized controlled trials. Int J Occup Med Environ Health. 2017;30(3):345-366.

136. Modini M, Tan L, Brinchmann B, et al. Supported employment for people with severe mental illness: systematic review and metaanalysis of the international evidence. Br J Psychiatry. 2016;209(1): 14-22.

137. Benach J, Muntaner C, Solar O, Santana V, Quinlan M. Introduction to the WHO Commission on Social Determinants of Health Employment Conditions Network (EMCONET) study, with a glossary on employment relations. Int J Health Serv. 2010;40(2): 195-207.

138. Benavides FG, Benach J, Diez-Roux AV, Roman C. How do types of employment relate to health indicators? Findings from the second European survey on working conditions. J Epidemiol Community Health. 2000;54(7):494-501.

139. Virtanen $M$, Kivimäki $M$, Joensuu $M$, Virtanen $P$, Elovainio $M$, Vahtera J. Temporary employment and health: a review. Int J Epidemiol. 2005;34(3):610-622.

140. Gewurtz RE, Cott C, Rush B, Kirsh B. The shift to rapid job placement for people living with mental illness: an analysis of consequences. Psychiatr Rehabil J. 2012;35(6):428-434.

141. Gottlieb L, Sandel M, Adler NE. Collecting and applying data on social determinants of health in health care settings. JAMA Intern Med. 2013;173(11):1017-1020.

142. Pinto AD, Glattstein-Young G, Mohamed A, Bloch G, Leung F-H, Glazier RH. Building a foundation to reduce health inequities: routine collection of sociodemographic data in primary care. J Am Board Fam Med. 2016;29(3):348-355.

143. Devoe JE, Bazemore AW, Cottrell EK, Likumahuwa-Ackman S, Spach N, Gold R. Perspectives in primary care: a conceptual framework and path for integrating social determinants of health into primary care practice. Ann Fam Med. 2016;14(2):104-108. 